DOI https://doi.org/10.30525/978-9934-26-004-9-117

\title{
ADAPTATION OF ARTISTIC AND COMPOSITIONAL CHARACTERISTICS OF PARAMETRIC DESIGN TO CONSTRUCTION OF STRUCTURE OF MODERN CLOTHES
}

\author{
Chuprina N. V. \\ Doctor of Arts, \\ Professor at the Department of Artistic Costume Modeling \\ Kyiv National University of Technology and Design \\ Kyiv, Ukraine \\ Kolosnichenko M. V. \\ Doctor of Technical Sciences, \\ Professor at the Department of Design, \\ Dean of the Faculty of Design \\ Kyiv National University of Technology and Design \\ Kyiv, Ukraine
}

In the arts and sciences, the phenomenon of parametric design originates in mathematics and physics. Parameter is a term used in conjunction with a model, surface, family, etc. The parametric curve, defined by the parametric equation or written in the coordinate graph, are beautiful wavy lines drawn for the artists in incredibly beautiful graphic compositions. Parametric design is the connection between elements of complex geometry and structures.

The basis of parametric design is a combination of computer tools and the desire of designers to go to the brink of variable data and form in the design and modeling of space and forms, both in architecture and in sculpture or modeling of a costume.

Computer technologies have given designers and architects the tools to analyze and model the complications observed in nature and the opportunity to apply them to the structural forms of building urban organizational models. The corresponding process is closely linked to parametric and creative thinking, the product of which is the creation of new generative forms [1].

Patrick Schumacher defined the parameterism style as the salvation of the architecture of the period of uncertainty that was created by the crisis of modernism. If all contemporary styles are somewhat limiting for designers, working with parameterism opens up original planning and modeling of space and shapes, both in architecture and in sculpture or costume design [2]. 

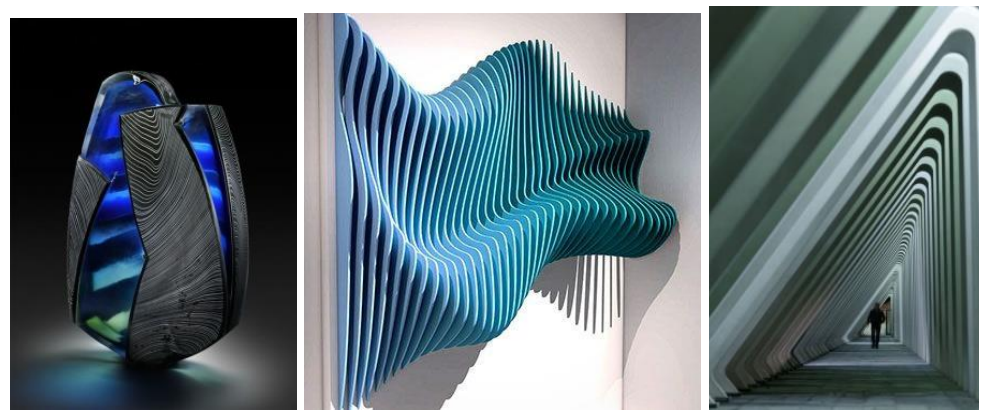

Fig. 1. Samples of art objects of parametric design [3]

The phenomenon of parametric design has been gaining ground since the late 1980s, especially in architecture. Not all artists have clear parametric principles of modeling, but not all can be Gaudi. Considered a pioneer of analog parametric design, he used the laws of physics for design instead of complex mathematical calculations.

The bridging personality who was able to calculate analog curves using computer programs is Ivan Sutherland, who owns a number of scientific discoveries in the field of software and who first discovered the calculation method for parametric software design.

Three of the world's leading architects singled out by us as being the foundations of modern parametric design are Greg Lynn, Massimiliano Fuchsas and Zaha Hadid. It is worth emphasizing that they are all leaders of teams that have been able to bring together a wide range of specialists who, in turn, in the future, will be able to continue to develop parametric design in the spatial environment. Theoretical works on this subject belong to Robert Woodbury and Vasim Jabi.

Renowned Japanese costume designer Yasutoshi Ezumi (Ezumi) has been inspired by parametric architectural gains from artists such as Ames, Frank Gehry and Gordon Matta-Clark since launching their brand in 2010. To display Yasutoshi Ezumi's Spring-Summer 2016 collection, a personal entry from Frank Gary about his own inspiration and sketching was used [4]. 

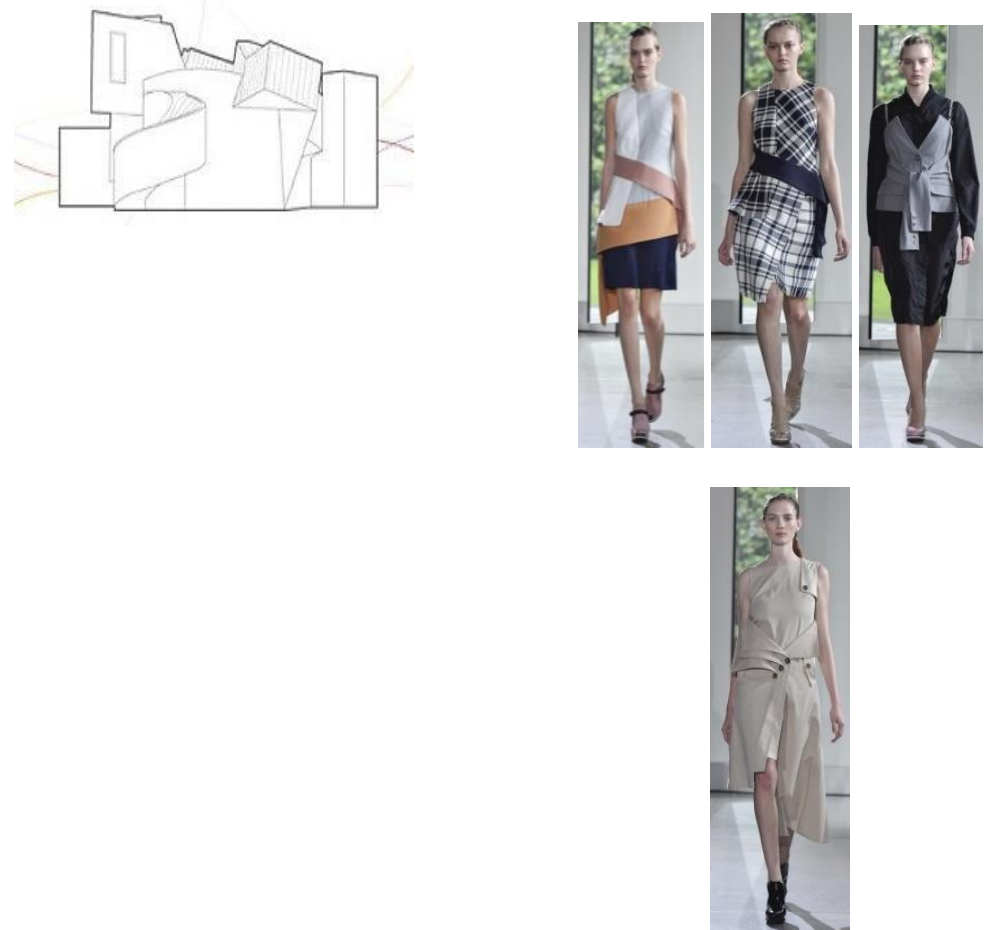

Fig. 2. Sketch for the project by architect F. Gehry [5]
Fig. 3. Fragments of the collection of designer brand Y. Ezumi, SS 2016 [4]

In the work it is substantiated that morphological analysis of objects of parametric design allows to distinguish its main features, namely: uniformity in lines and directions, rules of geometric progression, trajectory movement of elements and forms, structural, orderliness, ecology, original planning and modeling of space and forms, quiet end object view, convenient use (practicality), diagonal geometry, interaction of straight lines with contour, repetition of baselines / diagonals in structural elements in one $\mathrm{m}$ area. Designers Iris Van Harpen, Daniel Wrigg, Neri Oxman, who have an architectural background, combine mathematical algorithms and aesthetics to create complex 3D structures of parametric design. 

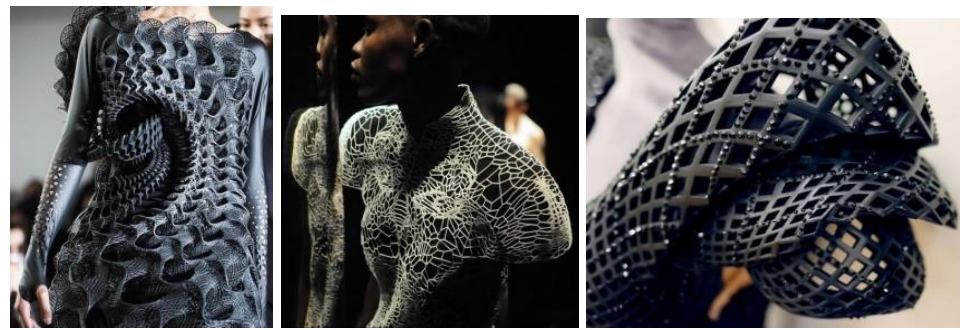

Fig. 4. Fragments of models of 3D printed clothing [6]

It is substantiated in the work that the morphological analysis of parametric design objects allows us to distinguish its main features, namely: uniformity in lines and directions, structure, orderliness, environmental friendliness, balanced final appearance of the object, convenient use (practicality), diagonal geometry, interaction of structural and composite lines with a silhouette, repetition of baselines / diagonals in structural elements in one direction. Objects created under the influence of parametric design successfully emphasize the rapidly progressing rhythm of life, its variability in the context of globalization and the demand for «future» aesthetics.

Based on the research results, the most characteristic elements of parametric design were identified in the work: longitudinal structured stripes (the so-called "pleated" fabric) articulations and reliefs (visually presented in folds on clothes) layering and complexity of cut; preference for a futuristic color scheme (complex color combination, submission of shades of the color of metal and chrome).

Given this, the presence of "structural" and orderliness inherent in parametrism through modeling and transformation of an architectural object in the design of clothes of various assortment is justified, has a single image, characterized by constancy, continuity and consistency.

Therefore, the phenomenon of parametric design, its history, origin and use is quite interesting for the designer to study and analyze. This allows you to find new inspiration for new projects. 


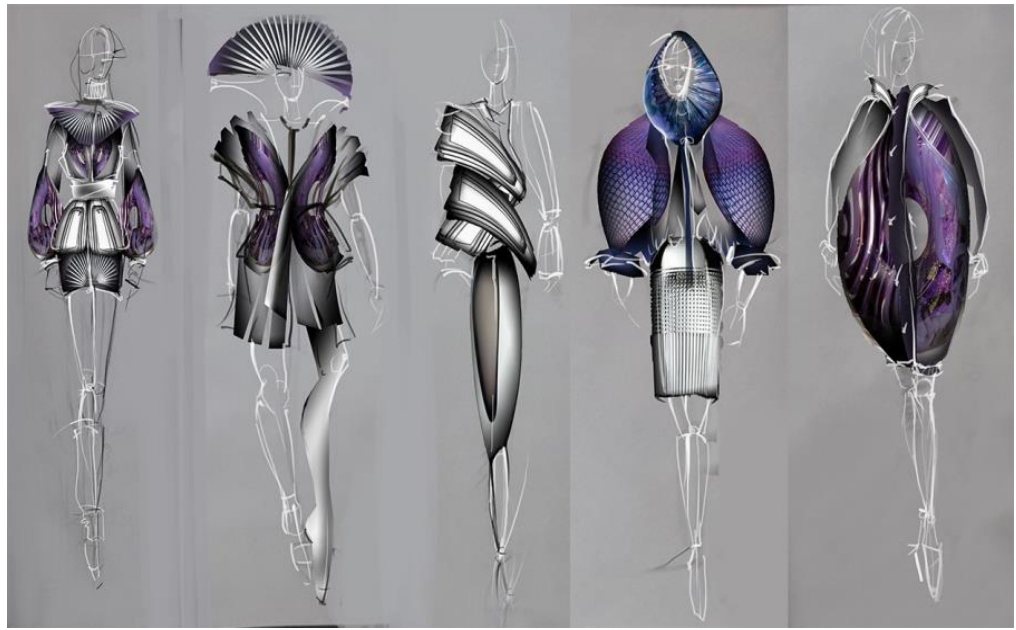

Fig. 5. Sketches of the author's collection of women's clothing, developed on the basis of the principles of parametric design (author Olishevskaya T.M., Faculty of Design KNUTD, 2019) [7]

\section{References:}

1. The official website of the magazine «Parametric Architecture». URL: https://parametric-architecture.com/amphibio-by-jun-kamei/___ (date_ of application 11.10.2018)

2. Schumacher P. Parametrism: a new global style in design and art. URL: https://yourforest.ua/parametricism-new-global-style-in-design-and-art (date of application 16.10.2019)

3. Parametric design. URL: https://www.pinterest.ru/ (date of application 16.10.2020)

4. The official website of the designer brand «Yasutoshi Ezumi». URL: https://yasutoshiezumi.com/ (date of application 14.12.2019)

5. Top 10: projects by Frank Gehry. URL: https://thearchitect.pro/ru/news/5388-TOP_10_proekty_Frenka_Geri (date of application 14.11.2020)

6. Printing clothes on a 3D printer: an extensive overview. URL: https://top3dshop.ru/blog/3d-printed-clothes-large-review.html (date of application 04.06.2020)

7. Kolosnichenko M.V., Chuprina N.V., Krotova T.F., Olishevska T.M. design of fashion clothing on the basis of parametric design principles. Art and design. 2020. №1. C. 129-141. (DOI:10.30857/2617-0272.2020.1.10) 